\title{
MATHEMATICAL MODELING, SIMULATION AND VALIDATION OF PHOTOVOLTAIC CELLS
}

\author{
Ravinder Kumar ${ }^{1}$, R Muralidharan ${ }^{2}$ \\ ${ }^{I}$ Department of Electrical and Computer Engineering, Caledonian College of Engineering, Oman \\ ${ }^{2}$ Department of Electrical and Computer Engineering, Caledonian College of Engineering, Oman
}

\begin{abstract}
In this paper, an analysis has been done on the effect of varying physical and environmental factors on the I-V (current voltage characteristics) of a photovoltaic cell using Matlab-Simulink. A standalone model has been created based on the mathematical relations between various parameters in photovoltaic cells made up of a single diode, a series resistance, and a shunt resistance. To validate the developed model, the values from I-V characteristics of this model have been compared with the experimental results. In addition, simulations have been done for I-V characteristics for different temperature and resistance values. The results obtained are analyzed and presented in this paper.
\end{abstract}

Keywords: Solar cell, Modeling, Matlab-simulink

\section{INTRODUCTION}

The influence of solar energy on the power sectors has increased its demand in the recent decades due to its abundant availability. A further help in terms of low cost production activities of photovoltaic/solar cells [1,2] is increasing its presence as a widespread one in the present scenario. These solar cells convert photon energy into electrical energy using photovoltaic effect and are made up of $\mathrm{p}-\mathrm{n}$ semiconductor junctions. Their current versus voltage (I-V) as well as P-V (Power versus Voltage) characteristics are highly non-linear. During absence of light energy, these cells produce what is known as dark current that has exponential characteristic I-V curves. The amount of energy harvested by them depends on the sun's irradiation and the ambient temperature. One of the major advantages of photovoltaic cells is that they are highly modular and by proper scaling, they can be expected to provide adequate power for various loads. Literature studies [2-10] have proven the interest taken by researchers on photovoltaic cells, especially in developing models using various softwares. The accuracy in simulation depends principally on the modeling, which includes the estimation of values used for I-V as well as P-V characteristics.

Researches have shown successfully the construction of mathematical model for a photovoltaic cell using the MATLAB/Simulink software. Tsai, et.al. [4] proposed a model built with a user-friendly icon and a dialog box similar to Simulink block libraries and this enabled the dynamics of PV power system to be easily simulated, analyzed, and optimized. Samer Said, et.al. [5] presented a PV array model using Matlab/Simulink with the assistance of SimPowerSystem toolbox and this model also facilitated simulating the dynamic performance of PV-based power systems. Asakpovi, et.al. [6] designed a model which can take excitation inputs from temperature, irradiance and voltage and their results confirmed the novel approach that they have chosen. Basim [7] proposed and constructed a simulation model making use of the two-diode model basic circuit equations of PV solar cell. This model considered the effect of sunlight irradiance and cell temperature on the output current I-V characteristic and output power $\mathrm{P}-\mathrm{V}$ characteristic. He compared the points obtained using model along with the manufacturer's model and concluded that they both produced an excellent correspondence in terms of values. Sakurang [8] proposed a simplified PV model to avoid any possible complications and also recommended for a fine tuning of parameters in his model for obtaining the successful result in modeling. To undergo construction of this model, the basic equation from the theory of semiconductors that mathematically describes the I-V characteristics of the ideal photovoltaic cell becomes necessary. These equations help in proving that the ideal solar cell theoretically can be modeled as a circuit with a current source in parallel with a diode. Pandiarajan, et.al. [9] provided a detailed modeling procedure for the circuit model with numerical dimensions using power system block set of MATLAB/Simulink and integrated with a DC-DC boost converter application. Rustemli, et.al. [10] simulated a photovoltaic model and tested it for various temperatures successfully. Researches are still in progress with high pace in this area.

In this paper, a Simulink model using single diode with shunt and series resistor is constructed based on the mathematical equations available. Its I-V characteristics are compared with the experimentally obtained characteristics for accuracy of the model. In addition to it, various other characteristics of the cell, namely, I-V characteristics for varying temperatures, for varying solar irradiation levels, and for various values of resistors, etc. are also tested. 


\section{PV SINGLE DIODE MODEL}

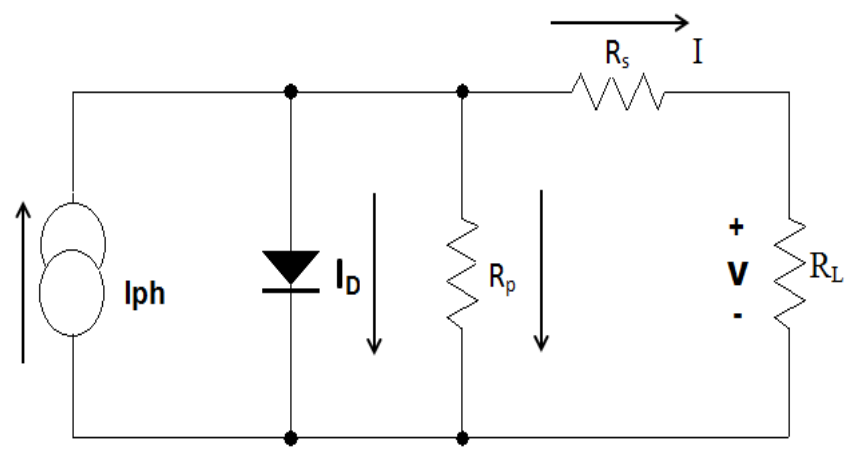

Fig -1: PV single diode model

Fig -1 [3] shows the single diode model of the PV cell that is duly constructed with a parallel current source to the diode, a shunt resistor $R_{p}$, a series resistor $R_{s}$ and a load resistor $R_{L}$. The basic equations [2,3] from the theory of semiconductors that mathematically describes the I-V characteristics of the ideal photovoltaic are given as follows:

$$
\mathrm{I}=\mathrm{I}_{\mathrm{ph}}-\mathrm{I}_{\mathrm{D}}
$$

where,

$$
\begin{gathered}
\mathrm{I}_{\mathrm{D}}=\mathrm{I}_{\mathrm{o}} \exp ((\mathrm{qV} / \mathrm{ak} \mathrm{T})-1) \\
\mathrm{I}=\mathrm{I}_{\mathrm{ph}}-\mathrm{I}_{\mathrm{o}} \exp ((\mathrm{qV} / \mathrm{akT})-1)
\end{gathered}
$$

In the above equations, $\mathrm{I}_{\mathrm{ph}}$ represents the current generated by the incident light, $I_{D}$ is the diode current and $I_{o}$ is the reverse saturation current of the diode, $\mathrm{q}$ is the electrical charge, $\mathrm{k}$ is the Boltzmann constant, $\mathrm{T}$ is the temperature of the $p-n$ junction, and 'a' is the diode ideality factor (constant). For an ideal photovoltaic cell, assuming there are no losses/leakages, this ideal cell can be modeled as a current source in parallel with a diode. Improving the PV cell model includes the effects of series and shunt resistance, and these are presented here in this paper.

To make an entry into simulation of a single diode PV cell model, it becomes customary to have a look at the accessories used along with the diode, namely, a current source in parallel, a shunt resistor for current flow and a series resistor implying the internal resistance for the current flow. The various parameters that are included in this model are: short circuit current, open circuit voltage, values of shunt and series resistor and finally, the ideality factor. The ideality factor has been taken to be unity here, even though it is a function of the voltage across the device.

The characteristic I-V curve will have the following points:

- $\quad \mathrm{I}_{\mathrm{sc}}$ : short circuit current referring to the maximum current produced by device under given conditions of light and temperature corresponding to zero output voltage. The power at this point is zero.
- $\mathrm{V}_{\mathrm{oc}}$ : Open circuit voltage referring to the maximum voltage from the device under given conditions of light and temperature corresponding to maximum voltage potential but zero current flow. The power at this point is also zero.

- $\mathrm{I}_{\mathrm{mp}}$ : current at maximum power referring to the current that results in maximum power under given conditions of light and temperature and is used as the rated current of a device.

- $\mathrm{V}_{\mathrm{mp}}$ : Voltage at maximum power referring to the current that results in maximum power under given conditions of light and temperature and is used as the rated voltage of a device.

Other than the above, the two other important parameters that influence the characteristics of solar cells are the Solar irradiance, an instantaneous quantity describing the rate of solar radiation (power) incident on a surface and Solar insolation referring to the amount of solar energy received on a surface.

Substituting for thermal voltage $\mathrm{V}_{\mathrm{T}}=\mathrm{kT} / \mathrm{q}$,

The expression for the photovoltaic current is given by:

$$
\mathrm{I}=\mathrm{I}_{\mathrm{ph}}-\mathrm{I}_{\mathrm{o}}\left[\exp \left(\frac{\mathrm{V}+\mathrm{I}_{\mathrm{R}} \mathrm{s}}{\mathrm{V}_{\mathrm{T}}}\right)-1\right]-\left(\frac{\mathrm{V}+\mathrm{I}_{\mathrm{R}} \mathrm{s}}{\mathrm{R}_{\mathrm{p}}}\right)
$$

and expression for voltage is given by

$$
\mathrm{V}=\mathrm{I}_{\mathrm{ph}} \cdot \mathrm{R}_{\mathrm{p}}-\mathrm{I}_{\mathrm{R}} \mathrm{R}_{\mathrm{p}}+\mathrm{I}_{\mathrm{o}}\left[\exp \left(\frac{\mathrm{V}+\mathrm{I}_{\mathrm{R}} \mathrm{s}}{\mathrm{V}_{\mathrm{T}}}\right)-1\right]-\mathrm{I}_{\mathrm{R}}
$$

In this paper, a single diode Simulink model of the PV cell with shunt and series resistor is constructed and its I-V characteristics (values) have been compared with the experimentally obtained characteristics for accuracy of the model. The cell that has been used here is the CEL (Central Electronics Limited) brand.

\section{RESULTS}

The single diode model has been created in Simulink as shown in Fig -2 using the current equations (3) and (4). Based on the model created, the I-V characteristics with variations in $\mathrm{I}_{0}$, temperature etc., have been simulated.

Fig -3 shows the simulated I-V Characteristics with $R_{s}=0.001$ ohms and $R_{p}=500$ ohms with variations in $I_{0}$. From this figure, it can be seen that when the value of $I_{o}$ is high, the current drops to zero rapidly. Fig -4 shows the simulated I-V characteristics with variations in series resistance keeping shunt resistance and $\mathrm{I}_{0}$ constant. Here the values for shunt resistance are chosen to be 500 ohms and $\mathrm{I}_{0}$ to be $2 \mathrm{nA}$. Fig -5 shows the simulated I-V characteristics with variations in shunt resistance keeping $R_{s}$ and $I_{0}$ to be constant. All the values are chosen in a random manner. Fig -6 shows the simulated I-V characteristics with variations in temperature. 


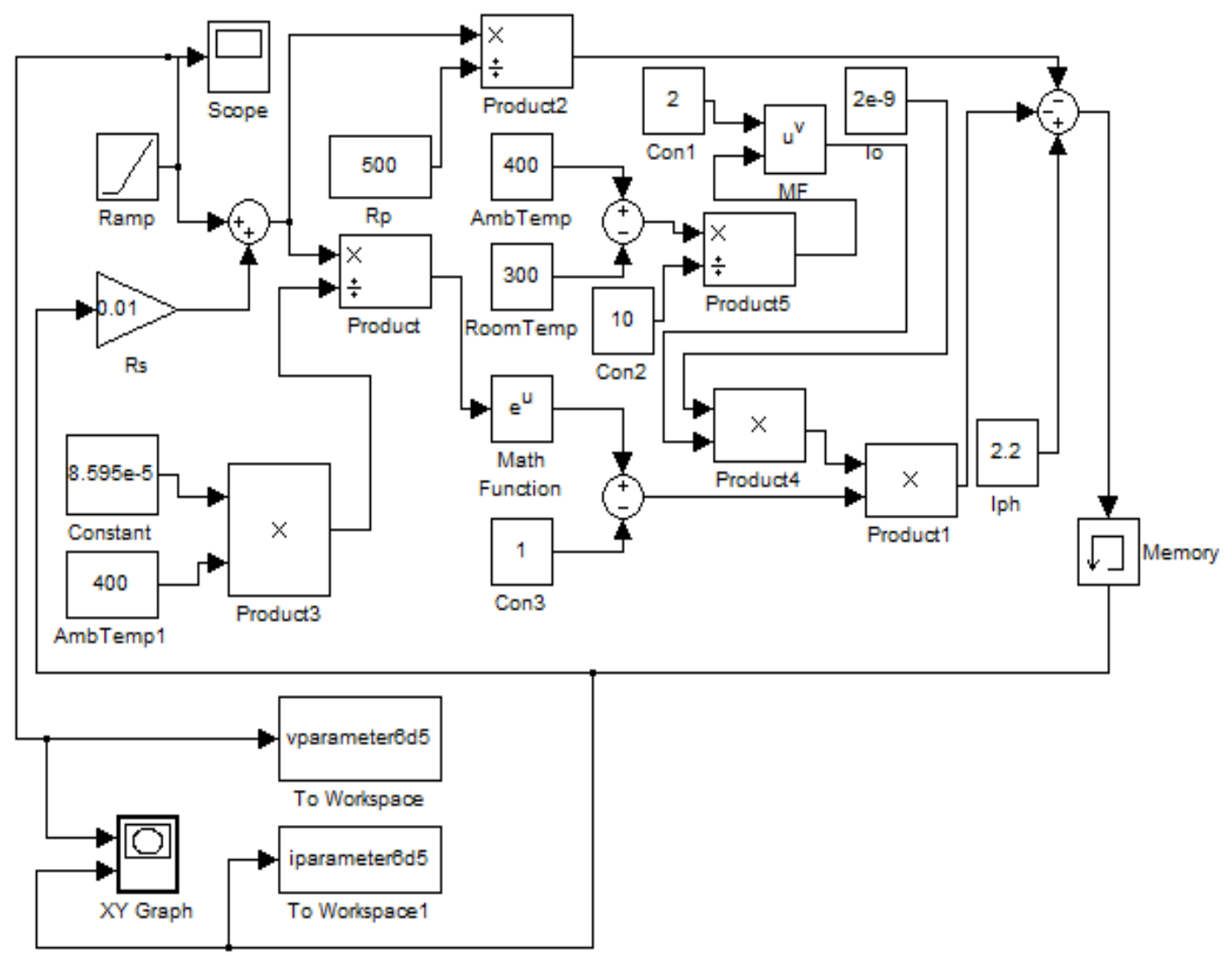

Fig -2: Simulink model of Single diode Photovoltaic cell

I-V characteristics with $R_{5}=0.01$ ohms and $R_{p}=500$ ohms

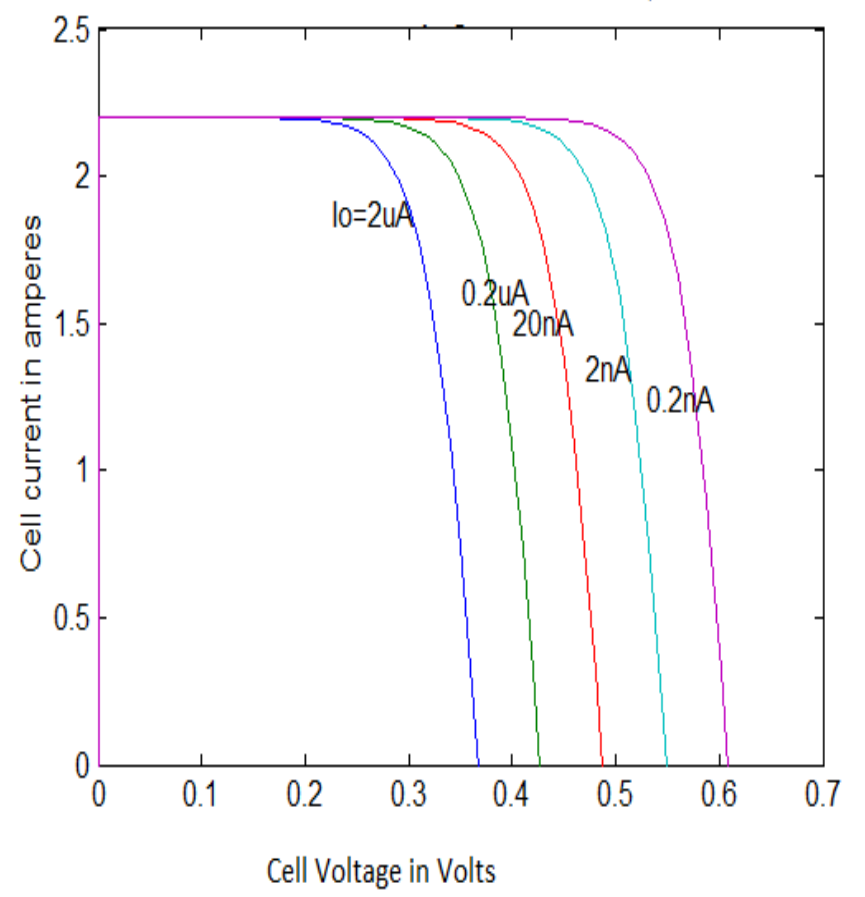

Fig -3: Simulated I-V characteristics for $\mathrm{I}_{\mathrm{o}}$ variations
I-V characteristics with $R_{p}=500$ ohms and variations in $R_{s}$

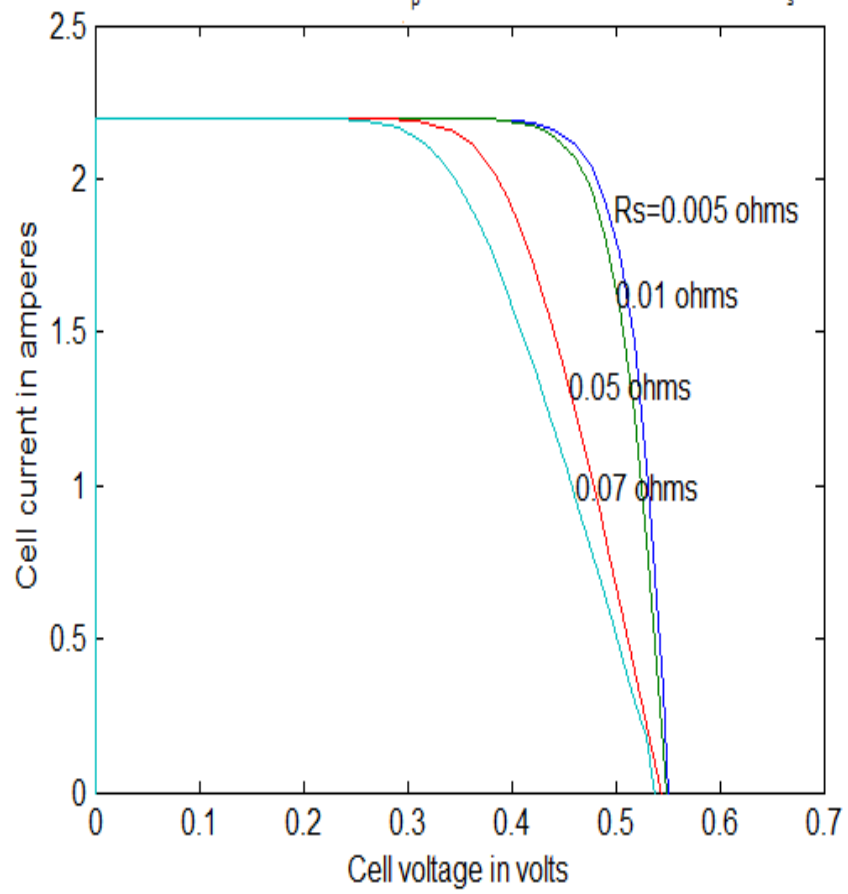

Fig -4: Simulated I-V characteristics for different values of series resistance $R_{S}$ and $I_{0}=2 n A$ 


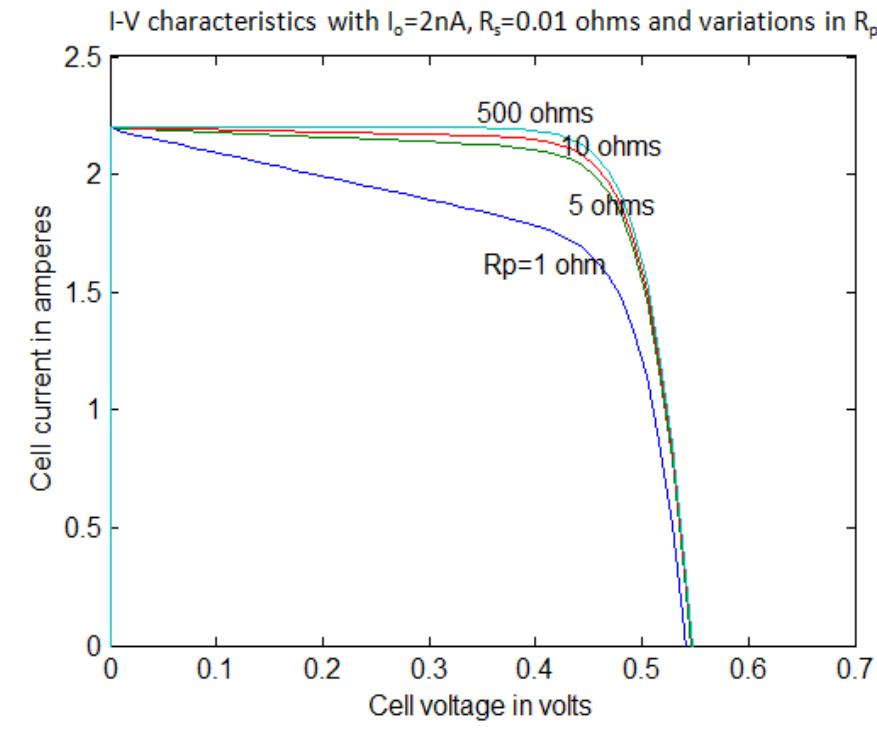

Fig -5: Simulated I-V characteristics for different $R_{p}$ values

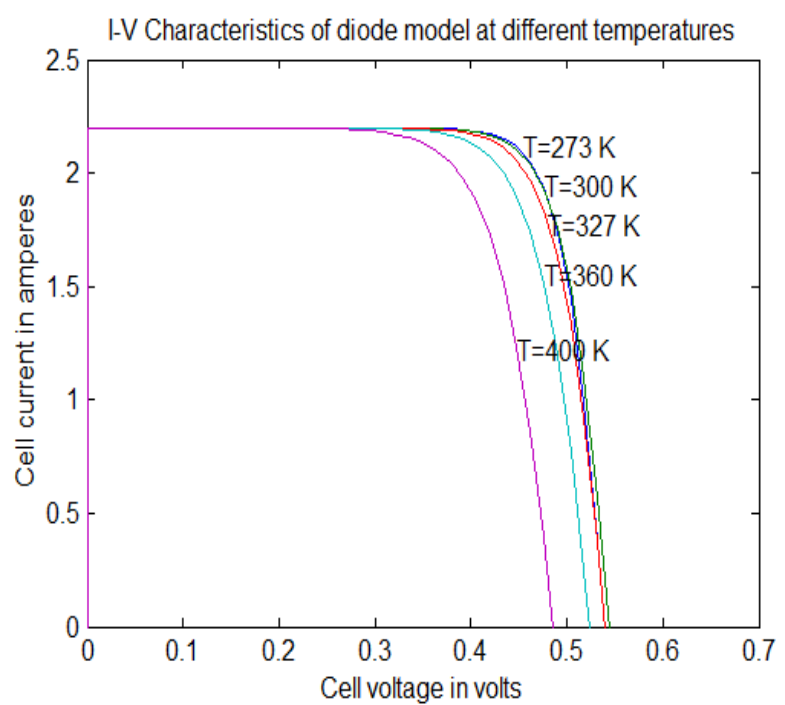

Fig -6: Simulated I-V characteristics for different temperatures

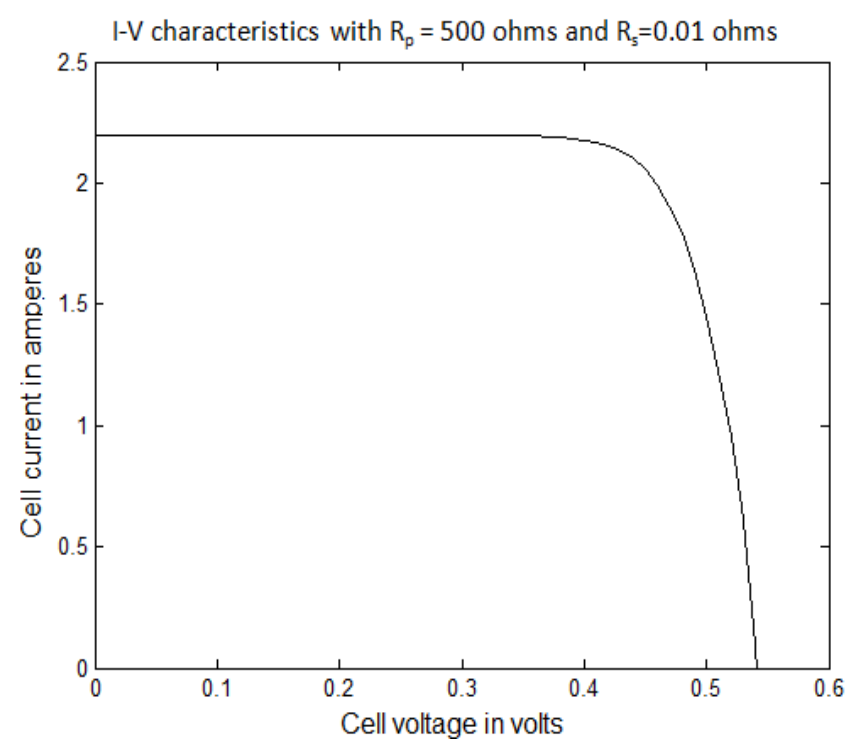

Fig -7: $I-V$ characteristics with $R_{s}$ and $R_{p}$
Fig-7 shows the I-V characteristics of the single diode model with resistor values of $R_{s}=0.01$ ohms and $R_{p}=500$ ohms. Again, the values are chosen in a random manner.

\subsection{Hardware Results}

The following parts and equipment have been used for obtaining hardware results, namely, a photovoltaic cell (CEL single cell), a variable resistance varying from $0.01 \Omega$ to $5 \Omega$, two voltmeters, and a Sun-simulator (which can give characteristics close to the actual one). The simulator is of 50 watt incandiscent bulb, which when placed in the close proximity of the cell gives the standard irradiance of 1000 watts $/ \mathrm{m}^{2}$. An ammeter is not desirable since any normal ammeter would have an internal resistance of $2 \Omega$ or greater instead of zero resistance. This, when connected in series to the cell, would alter the results drastically. A graph is plotted as shown in Fig -8 with Cell voltage in $\mathrm{x}$ axis and Cell current in y-axis.

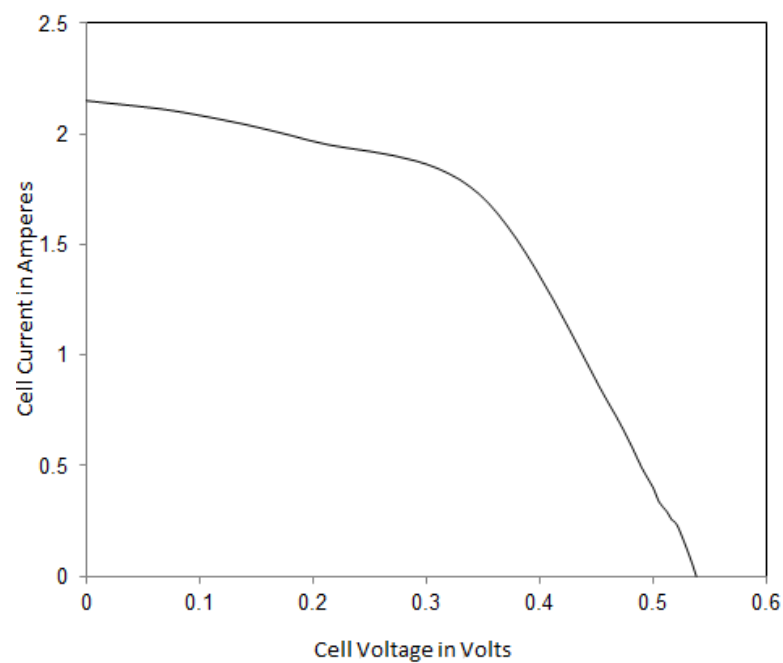

Fig -8: Hardware experimented results

Following cell values were obtained using calculations/extrapolations from the graph. $\mathrm{I}_{\mathrm{mp}}=1.72$ Amperes, $\mathrm{I}_{\mathrm{sc}}=2.15$ Amperes, $\mathrm{V}_{\mathrm{mp}}=0.346$ Volts, $\mathrm{V}_{\mathrm{oc}}=$ 0.538 Volts and maximum power across the load $\mathrm{P}_{\max }=0.6$ Watts. These were the values obtained for the first level of irradiance with one lamp ON out of five lamps in SunSimulator, which is assumed to be very close to the standard irradiance level of 1000 watts $/ \mathrm{m}^{2}$. These values appear to have a good agreement with the manufacturer's specifications of the photovoltaic cell.

\section{CONCLUSION}

In this paper, the behavior of the single diode model created using Simulink has been tested by comparing the I-V characteristics obtained using the model with the experimentally obtained values and a good agreement is obtained between the two characteristics. In addition to it, various other characteristics of the cell obtained using Simulink have also been studied. These studies included the temperature dependency as well as the solar irradiation levels on the I-V characteristics along with variations in the values of the resistors used. 


\section{REFERENCES}

[1] Solanki, C.S., "Solar Photovoltaics - Fundamentals, Technologies and Applications", Second Edition, Prentice Hall, 2013.

[2] Nehaoua, N., Chergui, Y and Mekki, D.E., "A New Model for extracting the Physical Parameters from IV Curves of Organic and Inorganic Solar Cells, Solar Cells - Silicon wafer based technologies,Prof. Leonid A. Kosaychenko (Ed.), 2011.

[3] Adel El Shahat, "PV Module Optimum Operation Modeling",Journal of Power technologies 94(1), 2014.

[4] Tsai,H.L., Tu,C.S., and Su,Y.J., "Development of Generalized Photovoltaic Model Using MATLAB/SIMULINK", Proceedings of the World Congress on Engineering and Computer Science 2008.

[5] Samer Said, Ahmed Massoud,Mohieddine Benammar and Shehab Ahmed, "A Matlab/Simulink-Based Photovoltaic Array Model Employing SimPowerSystems Toolbox", Journal of Energy and Power Engineering 6, 2012.

[6] Amevi Acakpovi, Essel Ben Hagan, "Novel Photo voltaic Module Modeling using Matlab/ Simulink", International Journal of Computer Application, Volume 83 - No.16, December 2013.

[7] Basim Alsayid, "Modeling and Simulation of Photovoltaic Cell/Module/Array with Two-Diode Model", International Journal of Computer Technology and Electronics Engineering (IJCTEE) Volume 1, Issue 3, June 2012.

[8] Sakurang, "Comparison Study of Solar PV Cell Modeling with Applications", Science and Engineering Symposium 4th International Science, Social Science, Engineering and Energy Conference, 2012.

[9] Pandiarajan, N., Ramaprabha, R., and Muthu. R., "Application of Circuit Model for Photovoltaic Energy Conversion System", Hindawi Publishing Corporation: International Journal of Photo Energy, 2012.

[10] Rustemli, S. and Dincer, F., "Modeling of Photovoltaic Panel and Examining Effects of Temperature in Matlab/Simulink", ISSN 1392-1215, No. 3(109), pp. 35-40, 2011. 